\title{
Neurokinin-1 receptor expression in inflammatory bowel disease: molecular quantitation and localisation
}

T Goode, J O'Connell, P Anton, H Wong, J Reeve, G C O’Sullivan, J K Collins, F Shanahan

Department of Medicine, National University of Ireland, Cork, Ireland T Goode J O'Connell

J K Collins

F Shanahan

Department of Surgery, National University of Ireland, Cork, Ireland G C O'Sullivan

Division of Digestive Diseases, University of California at Los Angeles, 675 Charles E Young Drive S, Los Angeles, CA 90095, USA

P Anton

H Wong

J Reeve

Correspondence to: F Shanahan, Department of Medicine, Clinical Sciences Building, University

Hospital, Cork, Ireland. Email:

fshanahan@bureau.ucc.ie

Accepted for publication 22 February 2000

\begin{abstract}
Background-Substantial evidence implicates the neuropeptide substance $P$ (SP) in mucosal immunoinflammatory responses. Autoradiographic studies have suggested a disturbance in SP receptor expression in inflammatory bowel disease (IBD).
\end{abstract}

Aims-Because of technical limitations such as poor cellular resolution with autoradiography, we used molecular methods to specifically localise the cellular expression of the neurokinin-1 receptor (NK-1R) in IBD colon, and to quantitate NK-1R mRNA expression levels therein.

Methods-In situ hybridisation and immunohistochemistry were used to localise NK-1R mRNA and protein, respectively, in normal, ulcerative colitis (UC), and Crohn's disease (CD) colonic resections. NK-1R mRNA expression levels of normal, UC, and CD mucosal biopsies were quantitated by competitive reverse transcription-polymerase chain reaction. Results-NK-1R expression was localised to lamina propria mononuclear cells, epithelium, submucosal vasculature, smooth muscle, and myenteric plexus of normal and IBD colon. No ectopic NK-1R expression was observed in IBD. However, we found increased numbers of NK-1R expressing lymphoid cells in IBD tissue, aberrant negative epithelial expression of NK-1R in UC, and increased expression of NK-1R in CD myenteric plexus. Quantitation of NK-1R mRNA expression in IBD colonic mucosal biopsies revealed marked upregulation of NK-1R mRNA levels compared with non-inflamed mucosal expression levels $(\mathrm{p}<0.01)$.

Conclusions-This report demonstrates the strategic localisation and upregulation of NK-1R expression in IBD colon, and thereby suggests the involvement of substance $P$ in the pathophysiological symptoms of IBD.

(Gut 2000;47:387-396)

Keywords: substance P; neurokinin-1 receptor; inflammatory bowel disease

Substantial evidence indicates that the neuropeptide substance $\mathrm{P}(\mathrm{SP})$ plays a role in inflammatory and immune responses. ${ }^{1} \mathrm{~A}$ spectrum of immunoregulatory effects has been described for this sensory neuropeptide. ${ }^{2}$ SP has been shown to influence lymphocyte traffic, ${ }^{3}$ lymphocyte proliferation, ${ }^{45}$ immunoglobulin production, ${ }^{4}{ }^{6}$ chemotaxis of neutrophils, ${ }^{7}$ phagocytosis of macrophages, ${ }^{8}$ and mast cell degranulation. ${ }^{9}$ Monocytes produce the inflammatory cytokines interleukin (IL)-1, IL-6, IL-10, and tumour necrosis factor $\alpha(\mathrm{TNF}-\alpha)$ in response to stimulation with SP. ${ }^{10}{ }^{11}$ The gastrointestinal tract is one of the most abundant sources of SP in the body. ${ }^{12}$ SP has been identified in extrinsic sensory neurones ${ }^{13}$ and in intrinsic enteric neurones of the gut, ${ }^{14}$ where it is known to modulate smooth muscle contractility, epithelial ion transport, vascular permeability, and immune function. ${ }^{12} 15$

Several lines of evidence implicate SP in the pathophysiology of certain experimental models of inflammatory bowel disease (IBD). ${ }^{16}$ Elevated levels of SP have been associated with Trichinella spiralis induced enteritis of rats $^{17}$ and mice. ${ }^{18}$ Blockade of SP with either SP antibodies $^{18}$ or with the SP antagonist CP $96,345^{19}$ markedly reduced jejunal inflammation of this parasitic infection. SP has also been shown to play an important role in Clostridium difficile toxin $\mathrm{A}$ enterocolitis. ${ }^{20}$ Administration of the specific SP receptor antagonists CP $96,345^{20}$ or CP $99,994,{ }^{21}$ or desensitisation of sensory nerves with capsaicin $^{2122}$ inhibited toxin A mediated fluid secretion and intestinal inflammation. SP receptor gene knockout mice were protected from epithelial cell damage, and the inflammatory and secretory changes induced by toxin $\mathrm{A}^{23}$ In the cotton-top tamarin model of spontaneous colitis, blockade of neurokinin-1 receptors by the SP antagonist LY-303870 blunted inflammation. ${ }^{24}$

Elevated levels of SP have been described in ulcerative colitis (UC), ${ }^{25-28}$ and have been shown to correlate with disease activity. ${ }^{2526}$ Several findings report an increased concentration of SP nerve fibres in the colon of UC patients. ${ }^{29-31}$ Recently, Watanabe et al found that the linear density of SP fibres increased significantly in UC patients with active disease. ${ }^{31}$ Other findings demonstrated a decrease in SP nerves in severe inflammatory

Abbreviations used in this paper: $\mathrm{CD}$, Crohn's disease; IBD, inflammatory bowel disease; LPMC, lamina propria mononuclear cells; NK-1R, neurokinin 1 receptor; RT-PCR, reverse transcription-polymerase chain reaction; qcRT-PCR, quantitative competitive RT-PCR; SP, substance P; UC, ulcerative colitis; IL, interleukin; TNF- $\alpha$, tumour necrosis factor $\alpha$; PBS, phosphate buffered saline. 
lesions of UC. ${ }^{32}$ Conflicting results have also been reported for Crohn's disease (CD). Mucosal SP levels were found to be significantly decreased in CD patients. ${ }^{25}$ Others have reported no significant difference between mucosal SP levels from CD patients and those of controls. ${ }^{27}$ An increased density of SP immunoreactive fibres has been demonstrated in $\mathrm{CD}$ colon. ${ }^{29}$ Compelling evidence for a disturbance in SP immunomodulation in IBD was described by Mantyh et al who demonstrated autoradiographically 1000 -fold upregulation of SP binding sites in the lymphoid follicles and vasculature of patients with IBD. ${ }^{33}$ They also reported increased expression of SP binding sites on enteric neurones of patients with active and quiescent $C D$, but not on enteric neurones of patients with UC. ${ }^{34}$

Interpretation of autoradiographic studies is hampered by such technical limitations as poor resolution, internalisation of receptors, ligand degradation, and promiscuity of ligand binding. Rapid agonist induced endocytosis of the SP (neurokinin-1) receptor has been observed both in vivo and in vitro. ${ }^{35}{ }^{36} \mathrm{SP}$ can also bind with lower affinity to many non-neurokinin receptors. ${ }^{37-39}$ The issue of SP receptor expression in IBD therefore needed to be readdressed. In the present study we used in situ hybridisation and immunohistochemistry to localise the cellular expression of neurokinin-1 receptor (NK-1R) mRNA and protein, respectively, in inflamed colonic tissue from IBD patients. We also used quantitative competitive reverse transcription-polymerase chain reaction (qcRT-PCR) to quantitate NK-1R mRNA expression levels in biopsies from non-inflamed and inflamed (IBD) colonic mucosa.

\section{Materials and methods}

TISSUE SPECIMENS

To obtain full thickness colonic sections for NK-1R immunohistology and in situ mRNA localisation, diseased colonic tissue was obtained from five patients undergoing surgical resection for UC (two women and three men; mean age 40 years) and from five patients undergoing surgical resection for $\mathrm{CD}$ (two women and three men; mean age 38 years). At the time of resection, three of the UC surgical patients and two of the CD surgical patients were receiving corticosteroid treatment. Control colonic tissue was obtained from five patients undergoing surgical resection for colorectal adenocarcinoma (four women and one man; mean age 72 years). For control samples, only histologically normal tissue from an uninvolved area of the colon was used. None of the control surgical patients was receiving corticosteroid treatment.

For NK-1R mRNA quantitation, colonic biopsies were taken from a group of patients undergoing investigative colonoscopy. These were different patients to those from whom resection specimens were obtained for NK-1R localisation. Biopsies were obtained from active lesions of 10 patients with UC (three women and seven men; mean age 37 years) and from active lesions of 10 patients with CD (three women and seven men; mean age 28 years). At the time of endoscopy, four of the UC patients and four of the CD patients were receiving corticosteroid treatment. Control colonic biopsies were obtained from nine patients with no inflammatory disease activity (four women and five men; mean age 49 years). None of the control patients was receiving corticosteroid treatment. All patients were diagnosed using clinical, radiographic, endoscopic, and histological criteria. ${ }^{40}$ Biopsies were snap frozen in liquid nitrogen and stored at $-70^{\circ} \mathrm{C}$ until further use. All protocols were approved by the University Teaching Hospitals Ethics Committee (Cork, Ireland).

LOCALISATION OF NK-1R MRNA EXPRESSION BY IN SITU HYBRIDISATION

In situ hybridisation was performed on paraffin embedded surgically resected human colon sections ( $4 \mu \mathrm{m}$ thick), mounted on aminopropylethoxysilane treated slides. Following deparaffinisation and rehydration, prehybridisation treatments involved washing $2 \times 5$ minutes each in (i) phosphate buffered saline (PBS), (ii) PBS, $0.1 \mathrm{M}$ glycine, (iii) PBS, $0.3 \%$ Triton $\mathrm{X} 100$, and (iv) PBS again. Sections were digested for 30 minutes at $37^{\circ} \mathrm{C}$ with proteinase $\mathrm{K}(10 \mu \mathrm{g} / \mathrm{ml}$ in $100 \mathrm{mM}$ Tris $\mathrm{HCl}, 50 \mathrm{mM}$ EDTA, $\mathrm{pH} 8.0$ ), fixed for five minutes at $4^{\circ} \mathrm{C}$ in $4 \%$ paraformaldehyde; PBS and then acetylated for $2 \times 5$ minutes in fresh $0.25 \%$ acetic anhydride; and $0.1 \mathrm{M}$ triethanolamine $(\mathrm{pH}$ 8.0). Sections were incubated at $37^{\circ} \mathrm{C}$ for 10 minutes in a prehybridisation buffer consisting of $50 \%$ formamide in $4 \times$ saline trisodium citrate (SSC) buffer. A digoxigenin labelled antisense RNA hybridisation probe (324 bp) corresponding to codons 230-338 of the human NK-1R cDNA sequence was synthesised from a recombinant plasmid clone (also used to construct the competitive standard for qcRT-PCR) by in vitro transcription with digoxigenin-11-UTP (Boehringer Mannheim) and T7 RNA polymerase. The nucleotide sequence of the NK-1R probe showed insignificant homology to any other sequences in the EMBL DNA sequence database. Hybridisation was performed at $42^{\circ} \mathrm{C}$ overnight in hybridisation buffer ( $50 \%$ formamide, $10 \%$ dextran sulphate, $1 \times$ Denhardt's reagent, $4 \times$ SSC, $10 \mathrm{mM}$ DTT, $500 \mu \mathrm{g} / \mathrm{ml}$ yeast tRNA, and $100 \mu \mathrm{g} / \mathrm{ml}$ of heat denatured herring sperm DNA) containing $1 \mathrm{ng} / \mathrm{ml}$ digoxigenin labelled riboprobe. After hybridisation, tissues were washed with increasing stringency to $0.1 \times \mathrm{SSC}$ at $37^{\circ} \mathrm{C}$. Hybridised probe was detected immunologically using alkaline phosphatase conjugated sheep antidigoxigenin antibody (Boehringer Mannheim, Mannheim, Germany) and visualised with NBT-BCIP (purple/ black precipitating product). Control slides involved competitive inhibition of hybridisation with a 10-fold excess of unlabelled antisense riboprobe. This resulted in a marked reduction in signal intensity thus confirming the specificity of the hybridisation.

IMMUNOHISTOCHEMICAL LOCALISATION OF NK-1R The NK-1R antibody was raised in rabbits against a synthetic peptide (MDNV- 
LPVDSDLSP) corresponding to the extracellular $\mathrm{N}$ terminal amino acids $1-13$ of human NK-1R. The IgG fraction was affinity purified on an AH-Sepharose column to which the peptide had been coupled. Antibody specificity was confirmed by extensive radioimmunoassays and western blotting.

Immunohistochemistry was performed on paraffin embedded surgically resected human colon sections ( $4 \mu \mathrm{m}$ thick), mounted on aminopropylethoxysilane treated slides. After deparaffinisation and rehydration, sections were microwaved in $10 \mathrm{mM}$ citrate buffer, $\mathrm{pH}$ 6.0, at $350 \mathrm{~W}$ for five minutes to assist antigen retrieval. Sections were immediately cooled in TBS (50 mM Tris HCl, pH 7.6, $150 \mathrm{mM}$ $\mathrm{NaCl}, 5 \mathrm{mM} \mathrm{KCl}$ ) and then washed twice for five minutes in wash buffer (TBS, $0.001 \%$ saponin). Endogenous peroxidase activity was quenched with $0.9 \%$ hydrogen peroxide in distilled water for 30 minutes. Sections were then washed in wash buffer containing $1 \%$ normal goat serum (used for all subsequent wash steps). Non-specific binding sites were blocked by incubation in wash buffer containing $5 \%$ normal goat serum for one hour. Sections were washed twice and then incubated overnight at $4^{\circ} \mathrm{C}$ with the rabbit polyclonal antihuman $\mathrm{NK}-1 \mathrm{R}$ specific IgG at a dilution of 1:50 in 50 $\mathrm{mM}$ Tris $\mathrm{HCl}, \mathrm{pH} 7.6$, and $1 \%$ normal goat serum. Antibody binding was localised using a biotinylated goat antirabbit IgG followed by avidin-biotin conjugated horseradish peroxidase (Vectastain Elite ABC detection kit, Vector Laboratories, Burlingame, California, USA). Antibody binding was visualised using 3',3' diaminobenzidine (Vector Laboratories) yielding a brown reaction product. Staining with isotype matched rabbit IgG was performed as a negative control. A specificity control was performed involving preadsorption of NK-1 R antibody with the immunising peptide $(100 \mu \mathrm{M})$ for 16 hours at $4^{\circ} \mathrm{C}$ prior to staining of sections.

QUALITATIVE DETECTION OF NK-1R mRNA EXPRESSION BY RT-PCR

Total RNA was isolated by phenol chloroform extraction of guanidinium isothiocyanate lysates. ${ }^{41} \mathrm{cDNA}$ was synthesised using approximately $100 \mathrm{ng}$ of total RNA, $9 \mathrm{U}$ of AMV reverse transcriptase (Promega Corp., Madison, Wisconsin, USA), $40 \mathrm{U}$ of RNAsin (Promega Corp.), $500 \mu \mathrm{M}$ of dNTPs, and 500 nM of SPR-specific antisense primer GGATTTCATTTCCAGCCCCT per $30 \mu$ reaction for 90 minutes at $42^{\circ} \mathrm{C}$.

NK-1R PCR was performed on the specific primed cDNA using the following sense and antisense primers, respectively: TGACCGCTACCACGAGCAAGTCTC and ATAGTCGCCGGCGCTGATGAAG corresponding to nucleotides 699-722 and 993-972 of human NK-1R cDNA, respectively. PCR primers were designed using the DNASTAR Lasergene Primerselect program (DNASTAR Inc., Madison, Wisconsin, USA). Primers were selected that showed insignificant homology to any other genes in the EMBL DNA sequence database. Primer pairs were chosen to span introns in their genomic sequences, thus ensuring mRNA specific amplification.

PCR was performed on $1 \%$ of the cDNA using a final concentration of $1.5 \mu \mathrm{M} \mathrm{MgCl}$, $50 \mu \mathrm{M}$ dNTPs, $0.1 \mu \mathrm{M}$ each primer, and 1 unit of Taq DNA polymerase (Promega Corp.) per $50 \mu \mathrm{l}$ reaction. The thermal cycling programme involved denaturation at $96^{\circ} \mathrm{C}$ for 15 seconds, annealing at $60^{\circ} \mathrm{C}$ for 30 seconds, and extension at $72^{\circ} \mathrm{C}$ for one minute 30 seconds, for 40 cycles, followed by a final extension at $72^{\circ} \mathrm{C}$ for 10 minutes. Negative controls were performed by either omitting reverse transcriptase from cDNA synthesis or by omitting cDNA from the PCR amplifications. As a positive control, RNA from cells known to abundantly express NK-1R mRNA were used: IM-9 B lymphoblastoid cell line. Hot start PCR was used to increase the specificity of the amplification. PCR products were analysed by electrophoresis through $2 \%$ agarose gels and viewed under UV light after ethidium bromide staining. Product specificity was confirmed by DNA sequence analysis using an ABI Prism 310 Genetic Analyser (Perkin-Elmer, Norwalk, Connecticut, USA). Hae III digested $\phi$ X174 DNA size markers were used.

QUANTITATION OF NK-1R MRNA EXPRESSION BY QUANTITATIVE COMPETITIVE RT-PCR (qcRT-PCR) To facilitate quantitation of NK-1R mRNA, a competitive internal RNA standard was constructed. ${ }^{42}$ This standard was identical to the target NK-1R sequence except for an internal deletion of $71 \mathrm{bp}$. Construction of the competitive standard involved cloning a NK-1R PCR product (324 bp) into pBluescript (Stratagene, La Jolla, California, USA) at the EcoRV site. This NK-1R PCR product was obtained using the following sense and antisense primers respectively: GACTCCTCTGACCGCTACCA and GGATTTCATTTCCAGCCCCT corresponding to nucleotides 691-710 and 1014-995 of the human NK-1R cDNA, respectively. Orientation of the PCR product insert within the plasmid was determined by restriction mapping with HinfI. Digestion at the BsrGI and $\mathrm{Bgl}$ II unique restriction sites within the cloned insert resulted in deletion of a $71 \mathrm{bp}$ fragment. Sticky ends of the plasmid were then filled in by Klenow DNA polymerase (Promega Corp.) and blunt ended recircularisation of the plasmid was performed using T4 DNA ligase (Promega Corp.). Following propagation in $E$ coli, the deleted recombinant plasmid was subjected to in vitro transcription with T3 RNA polymerase (Promega Corp.) to synthesise deleted sense RNA transcripts (257 bp) for use as a competitive standard in qcRT-PCR.

For qcRT-PCR, varying amounts of RNA standard transcripts of known concentration were spiked into aliquoted target RNA sample, and the mixtures were then subjected to RT-PCR, as described above. As the internal standard is spiked in at the cDNA synthesis step, competition for both reverse transcription and PCR amplification occurs. Equivalence of PCR products occurs when target and standard templates are present in equal initial 
concentrations, permitting quantitation of the target template. Equivalence was determined as the point where target and competitive standard PCR products were of equal band intensity. Results for NK-1R mRNA quantitation were expressed as number of NK-1R mRNA molecules per $\mu \mathrm{g}$ of total RNA isolated. Total RNA was quantified using a nucleic acid quantitation kit (Invitrogen BV, the Netherlands). The accuracy, sensitivity, and reproducibility of the qcRT-PCR assay have been validated in control experiments. ${ }^{42}$ The assay is sufficiently sensitive to quantitate $100 \mathrm{NK}-1 \mathrm{R}$ mRNA copies (corresponding to $10^{3} \mathrm{NK}-1 \mathrm{R}$ mRNA transcripts/ $\mu \mathrm{g}$ RNA isolated).

A third band of slower electrophoretic mobility than the target and competitor PCR products was observed (at $360 \mathrm{bp}$ ) when target and competitor PCR products were both present at relatively high concentrations. To confirm that this was due to heteroduplex formation between one strand of target and one strand of competitor PCR products, digestion with the single stranded DNA specific nucle-
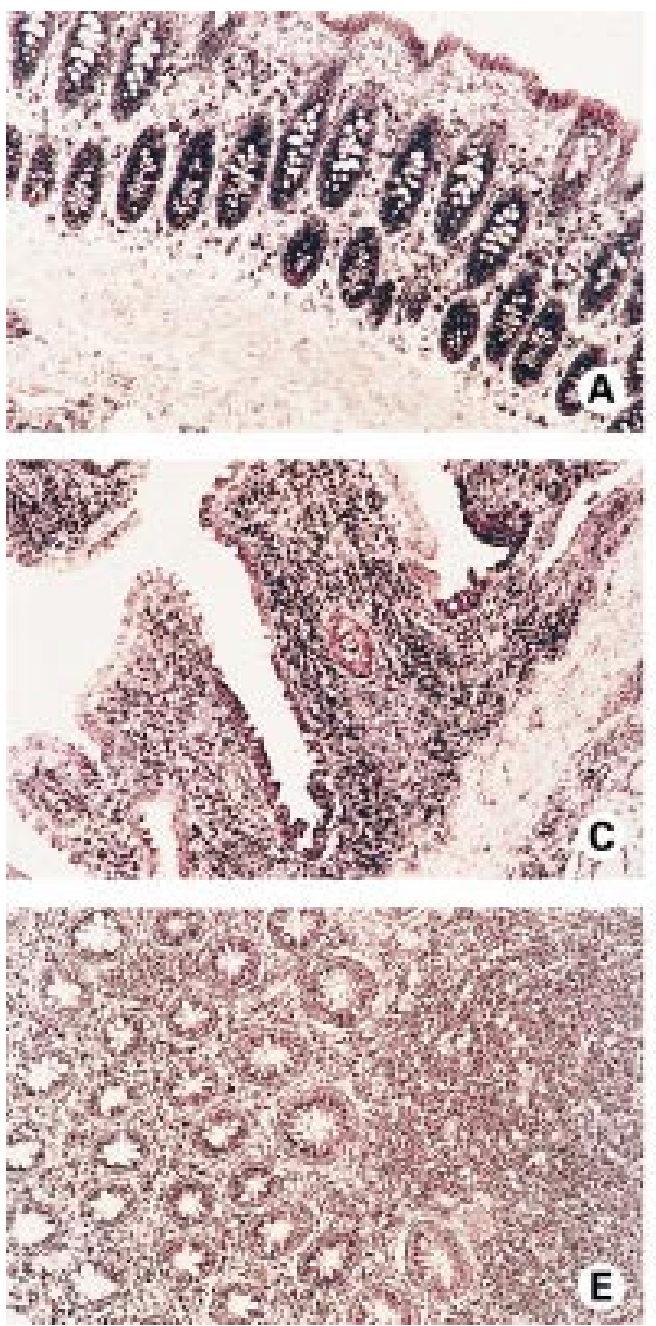

Figure 1 Localisation of neurokinin-1 receptor (NK-1R) $m R N A$ expression in non-inflamed colon $(A, B)$, in active ulcerative colitis (UC) colon $(C, D)$, and in active Crohn's disease (CD) colon $(E, F)$ by in situ hybridisation. (A)

NK-1R mRNA (purple) is detected in lamina propria mononuclear cells (LPMC), and in surface and crypt epithelium of normal colon. (C) NK-1R mRNA expression (purple) by LPMC and epithelial cells of UC colon. Note the "patchy" positivity of surface epithelium. (E) Expression of NK-1R $m R N A$ (purple) by LPMC and crypt epithelium of CD colon. Note the dense inflammatory infiltrate of $N K-1 R m R N A$ expressing cells. $(B, D, F)$ Control hybridisation of consecutive sections of normal (B), UC (D), and CD (F) colon, with a 10-fold excess of unlabelled riboprobe. Signal intensity is dramatically reduced, confirming the specificity of hybridisation. ase, S1, was performed. Digestion was performed at $37^{\circ} \mathrm{C}$ for 30 minutes with 1 unit of S1 nuclease (Promega Corp.) per $\mu \mathrm{g}$ of RT-PCR products.

STATISTICAL ANALYSIS

Quantitative RT-PCR results were expressed as NK-1R mRNA molecules per $\mu \mathrm{g}$ of total RNA isolated. The non-parametric Mann-Whitney test was used for statistical comparison. Differences with $\mathrm{p}<0.05$ were considered to be statistically significant.

\section{Results}

EXPRESSION OF NK-1 RECEPTOR IN NORMAL

To evaluate the pathological implications of NK-1R in IBD it was first necessary to determine the cellular expression of NK-1R in normal colon. We have previously mapped expression of NK-1R in non-inflamed colonic mucosa. ${ }^{43}$ In the present report, we used the techniques of in situ hybridisation and
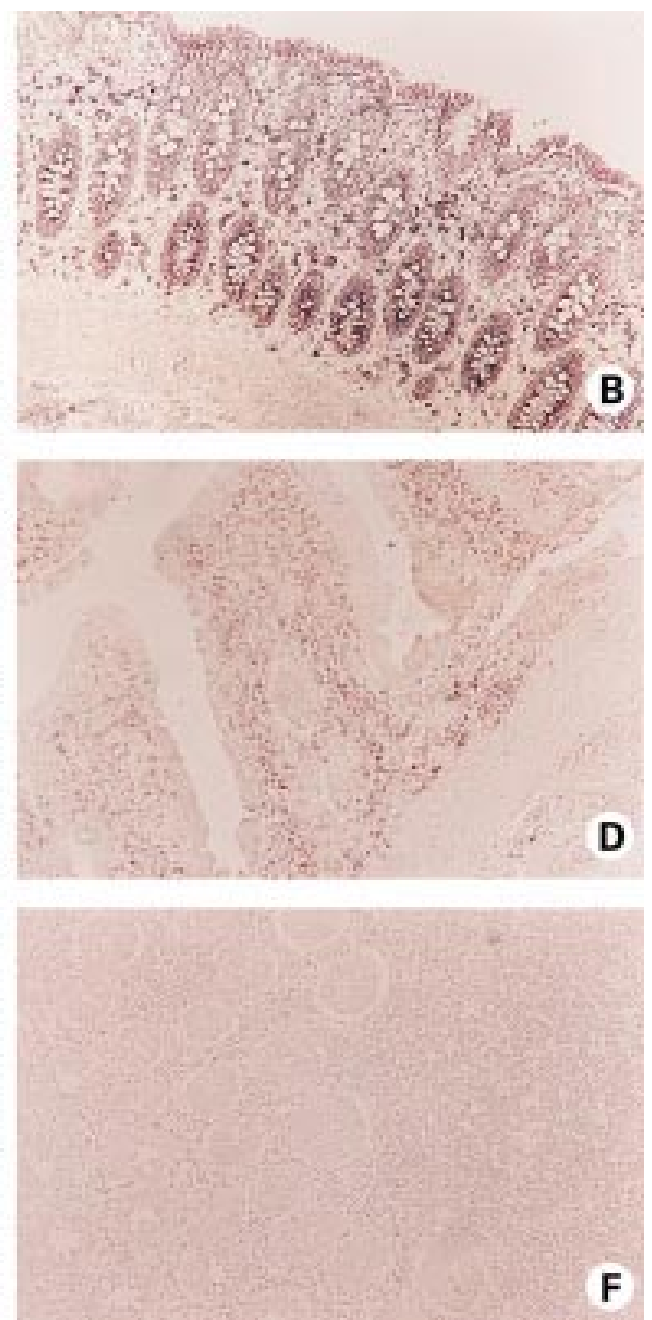

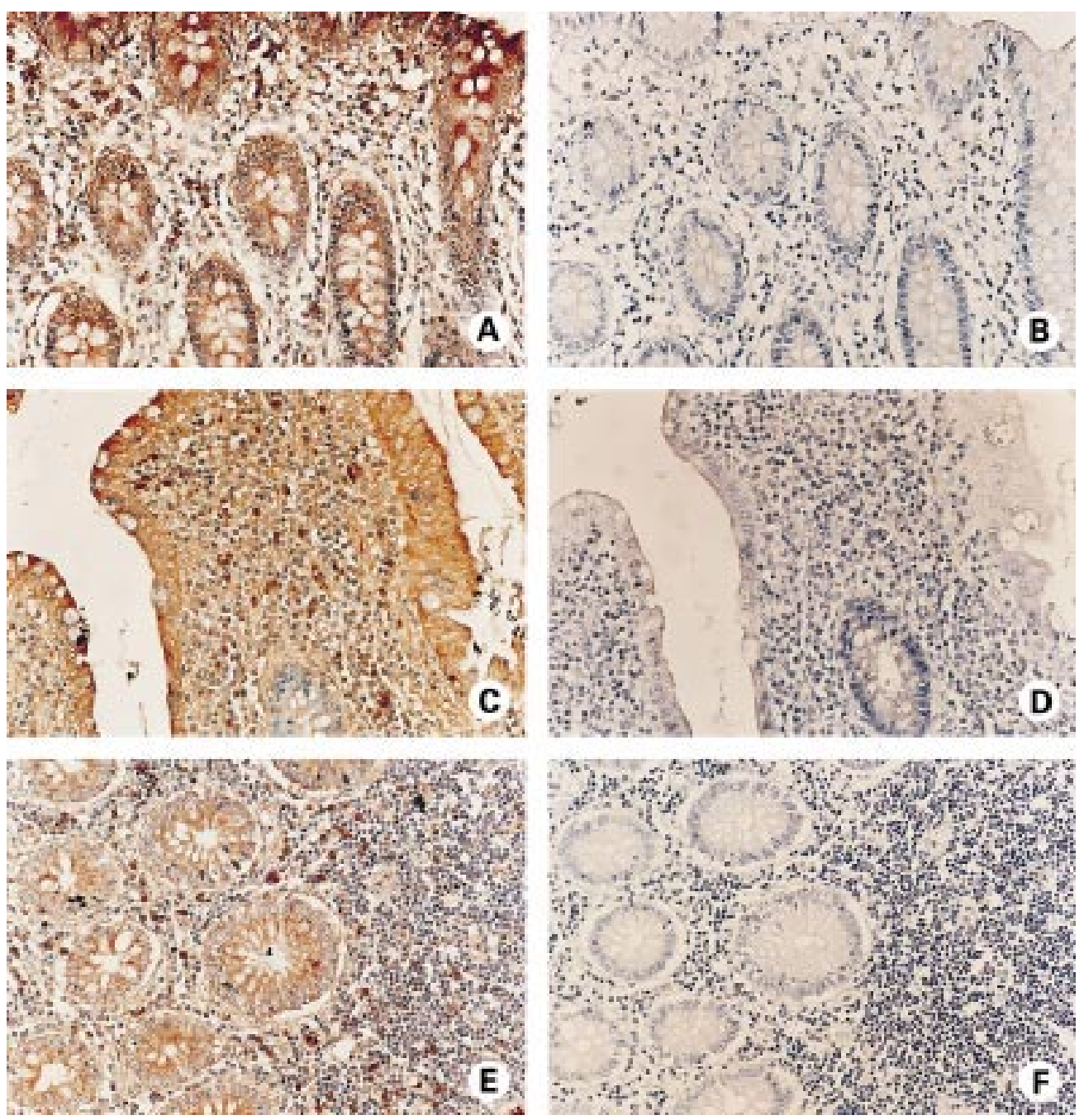

Figure 2 Immunohistochemical localisation of neurokinin-1 receptor (NK-1R) protein expression in non-inflamed colon $(A, B)$, in active ulcerative colitis $(U C)$ colon $(C, D)$, and in active Crohn's disease $(C D)$ colon $(E, F)$. Sections are consecutive to those processed for in situ hybridisation in fig 1 and are shown at higher magnification. (A) NK-1R immunoperoxidase staining (brown) is detected in lamina propria mononuclear cells (LPMC), and in surface (top right of figure) and crypt epithelium of normal colon. (C) NK-1R expression (brown) is present in LPMC and in surface epithelium of UC colon. Note the crypt epithelium is negative for NK-1R expression (blue). (E) Expression of NK-1R protein (brown) by LPMC and crypt epithelial cells of $C D$ colon. $(B, D, F)$ Control staining of consecutive sections of normal (B), UC (D), and CD (F) colon. Specificity of antibody binding was confirmed, as preincubation of the primary antibody with the NK-1R immunising peptide inhibited staining. All sections were counterstained with haematoxylin (blue).

immunohistochemistry to examine cellular expression of NK-1R mRNA and protein, respectively, in full thickness normal colon sections.

NK-1R mRNA expression localised to lamina propria mononuclear cells (LPMC), lymphoid follicles, and to surface and crypt epithelium of non-inflamed colon (fig 1A), thus confirming our previous results. ${ }^{43} \mathrm{mRNA}$ expression also localised to submucosal arterioles and venules, circular and longitudinal smooth muscle layers, and to enteric neurones of the myenteric plexus (see fig $4 \mathrm{~A}, \mathrm{C}$ ). Hybridisation specificity was confirmed as a 10 -fold excess of unlabelled riboprobe resulted in a dramatic reduction in hybridisation signal intensity (fig 1B). Using immunohistochemistry, NK-1R protein expression gave a similar cellular distribution to that observed for NK-1R mRNA: NK-1R protein was detected in LPMC, lymphoid follicles, surface and crypt epithelium, submucosal arterioles and venules, longitudinal and circular smooth muscle, and in myenteric plexus neurones (figs $2 \mathrm{~A}, 4 \mathrm{E}$ ). The specificity of antibody binding was confirmed, as staining was competitively inhibited by preincubation of the primary antibody with the NK-1R-immunising peptide (fig 2B).

EXPRESSION OF NK-1 RECEPTOR IN IBD COLON Using the techniques of in situ hybridisation and immunohistochemistry, NK-1R expression was localised to LPMC, lymphoid follicles, and epithelium of inflamed UC and CD colon (figs 1C, 1E, 2C, 2E). Expression was also evident in submucosal arterioles and venules, in circular and longitudinal smooth muscle layers, and in enteric neurones of the myenteric plexus of both $\mathrm{UC}$ and $\mathrm{CD}$ resected colon (figs 3C, 4B, 4D, 4F). Vascular expression of NK-1R was further localised to the endothelial lining and muscularis of submucosal arterioles and venules (fig 3C). Cellular expression of NK-1R protein exactly matched that observed for NK-1R mRNA. In other 

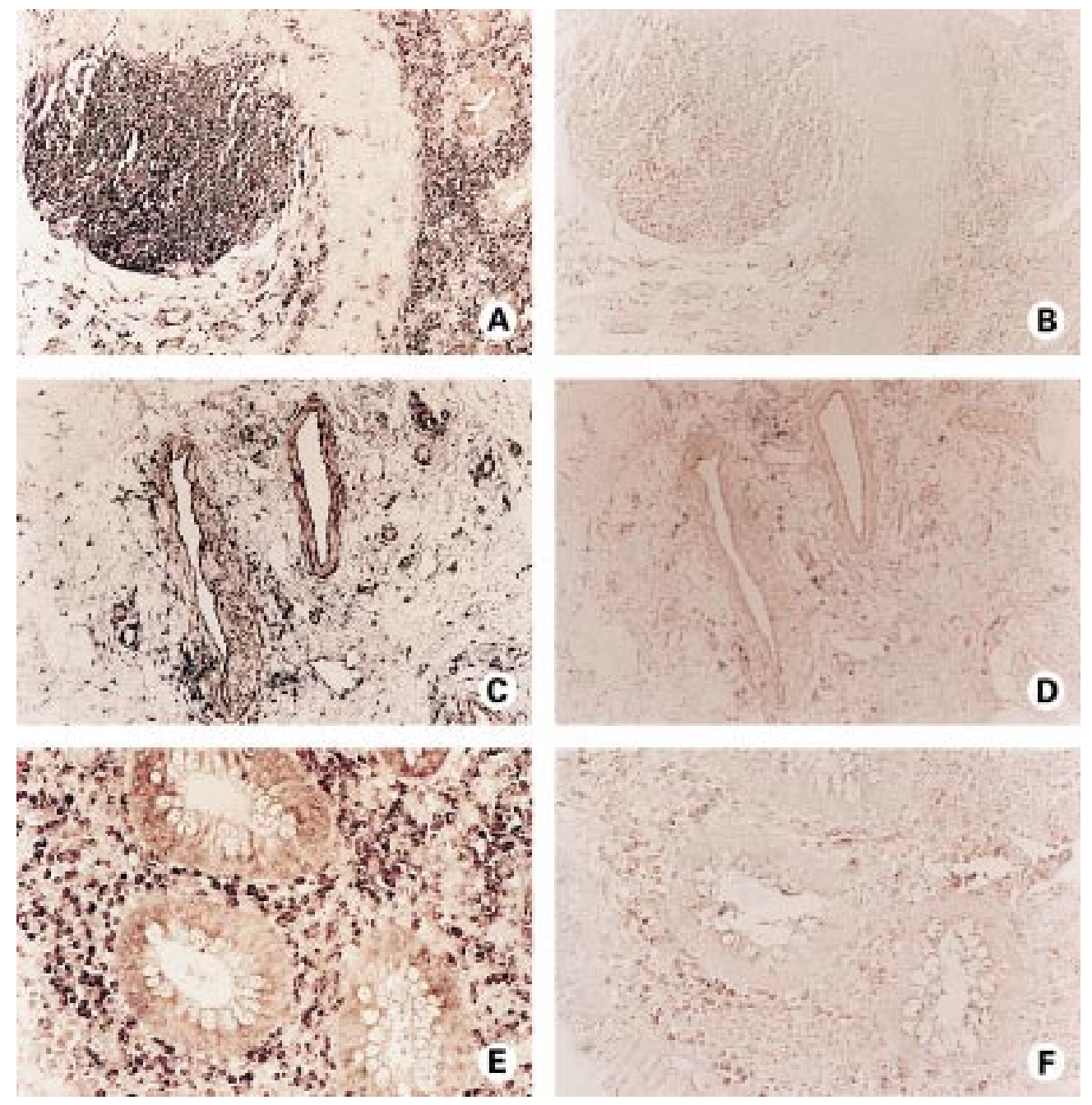

Figure 3 Localisation of neurokinin-1 receptor (NK-1R) mRNA expression in active ulcerative colitis (UC) colon by in situ hybridisation. (A) NK-1R mRNA expression (purple) is detected in lamina propria mononuclear cells (LPMC) and in a lymphoid follicle of $U C$ colon. Crypt epithelial cells negative for NK-1R $m R N A$ are present. (C) Expression of NK-1R $m R N A$ by submucosal arterioles and venules of UC colon. $m R N A$ expression (purple) is evident in the endothelium and muscularis of blood vessels. (E) High magnification view of crypt epithelial cells negative for NK-1R mRNA expression, surrounded by NK-1R positive (purple) LPMC in UC colon. $(B, D, F)$ Control hybridisation of consecutive sections of UC colon, with a 10-fold excess of unlabelled riboprobe. Signal intensity is dramatically reduced, confirming specificity of hybridisation.

words, no ectopic expression of NK-1R was observed in IBD colon. Appropriate controls confirmed the specificity of riboprobe hybridisation (fig 1D, 1F) and antibody binding (fig $2 \mathrm{D}, 2 \mathrm{~F})$, respectively.

In the non-inflamed colon, we have previously localised NK-1R expression to the majority of LPMC in situ, and to a broad range of LPMC subsets ex vivo, including CD4, CD45R0, CD45RA, CD8, CD19, and CD14 positive cells. ${ }^{43}$ The majority of LPMC of inflamed UC and CD colon were also positive for $\mathrm{NK}-1 \mathrm{R}$ expression (figs $1 \mathrm{C}, 1 \mathrm{E}, 2 \mathrm{C}, 2 \mathrm{E}$ ), as were lymphoid follicles (fig 3A), suggesting a subset unrestricted expression of $\mathrm{NK}-1 \mathrm{R}$ in LPMC of inflamed colon.

Aberrant negative epithelial expression of NK-1R was noted in active UC. As illustrated in fig $1 \mathrm{C}, \mathrm{NK}-1 \mathrm{R}$ expressing surface epithelial cells are interspersed by NK-1R negative epithelial cells in UC colon. This observation of aberrant negative epithelial expression was also frequently detected in crypt epithelial cells of UC colon (figs 2C, 3A, 3E). The loss of epi- thelial NK-1R expression occurred in all UC specimens $(n=5)$, irrespective of corticosteroid treatment $(n=3 / 5)$, and was very rarely observed in $C D$ epithelia (figs $1 \mathrm{E}, 2 \mathrm{E}$ ). Intense staining of the myenteric plexus was evident in CD colon compared with normal (fig 4) or UC colon (data not shown). This increased NK-1R detection could perhaps be attributed to hyperplastic neurones known to be characteristic of $\mathrm{CD},{ }^{44}$ or to lymphoid cells (NK-1R expressing) which have been shown to infiltrate the plexus in CD (fig 4B, 4D). ${ }^{45}$

Localisation of NK-1R mRNA and protein were consistent for all specimens within each group (control, UC, and $\mathrm{CD} ; \mathrm{n}=5$ each). Localisation of NK-1R expression in IBD patients was not affected by corticosteroid treatment (UC n=3/5; CD n=2/5).

NK-1R mRNA EXPRESSION IS UPREGULATED IN IBD COLONIC MUCOSA

We have previously developed a qcRT-PCR assay to accurately quantify NK-1R mRNA expression. ${ }^{42}$ Figure 5 illustrates quantitation of 
NK-1R mRNA expressed in a particular UC biopsy sample. Equivalence of PCR amplification products is seen at $4.1 \times 10^{3} \mathrm{NK}-1 \mathrm{R} \mathrm{mRNA}$ molecules, in which target (295 bp) and competitive standard (228 bp) PCR products are of equal band intensity. When adjusted for the amount of total RNA in the assay, this represents a level of expression of $4.1 \times 10^{4} \mathrm{NK}-1 \mathrm{R}$ mRNA transcripts/ $\mu \mathrm{g}$ RNA. The higher molecular weight band ( $(360 \mathrm{bp})$ seen on the gel is due to heteroduplex formation between one strand each of target (295 bp) and competitor (228 bp) PCR products. The unannealed portion of the target strand, corresponding to the sequence deleted from the competitive standard, loops out to form a bulky secondary structure that results in slower electrophoretic mobility than either of the two linear products of the competitive PCR. Digestion with the single stranded DNA specific nuclease, S1, eliminated the $360 \mathrm{bp}$ band (fig 5B). This confirmed that the $360 \mathrm{bp}$ band was the predicted heteroduplex containing a single stranded "loop-out" amenable to S1 digestion. This type
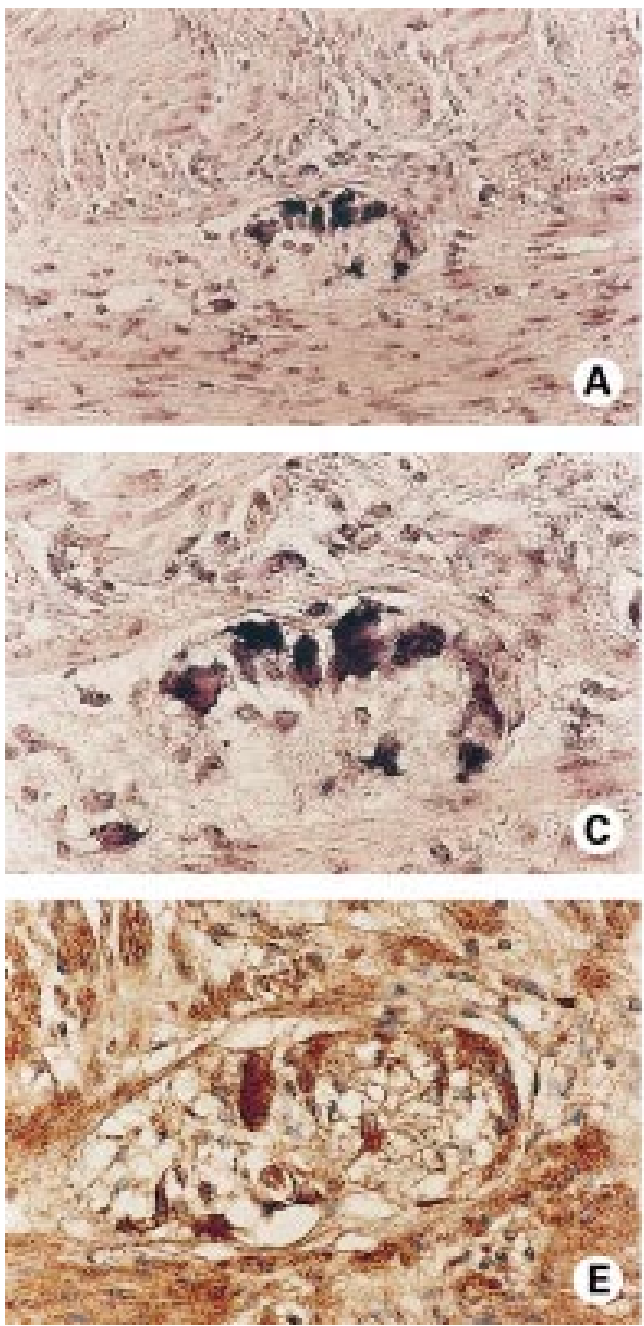

of heteroduplex is commonly observed in competitive PCR, but as the heteroduplex consists of a hybrid of one strand from target and competitor products, it does not bias the normal occurrence of equivalence and hence quantitation. ${ }^{42} 46$

The mean level of expression of NK-1R mRNA in biopsies from non-inflamed mucosa was found to be $0.9 \times 10^{4} \mathrm{NK}-1 \mathrm{R}$ mRNA transcripts/ $\mu$ g total RNA (n=9) (fig 6). Biopsies from active lesions of UC patients exhibited increased NK-1R mRNA levels and yielded a mean of $1.8 \times 10^{4} \mathrm{NK}-1 \mathrm{R}$ transcripts/ $\mu \mathrm{g}$ total RNA ( $n=10)$. However, this increase did not reach statistical significance $(\mathrm{p}<0.1)$. In active $\mathrm{CD}$, the mean level of NK-1R mRNA expression in mucosal biopsies was $6.3 \times 10^{4} \mathrm{NK}-1 \mathrm{R}$ transcripts/ $\mu$ g total RNA ( $\mathrm{n}=10)$. This sevenfold upregulation in NK-1R mRNA relative to normal mucosal mRNA levels was statistically significant $(p<0.01)$. NK-1R mRNA levels from $C D$ mucosa were also significantly increased compared with expression levels from UC mucosa $(p<0.01)$. IBD mucosal
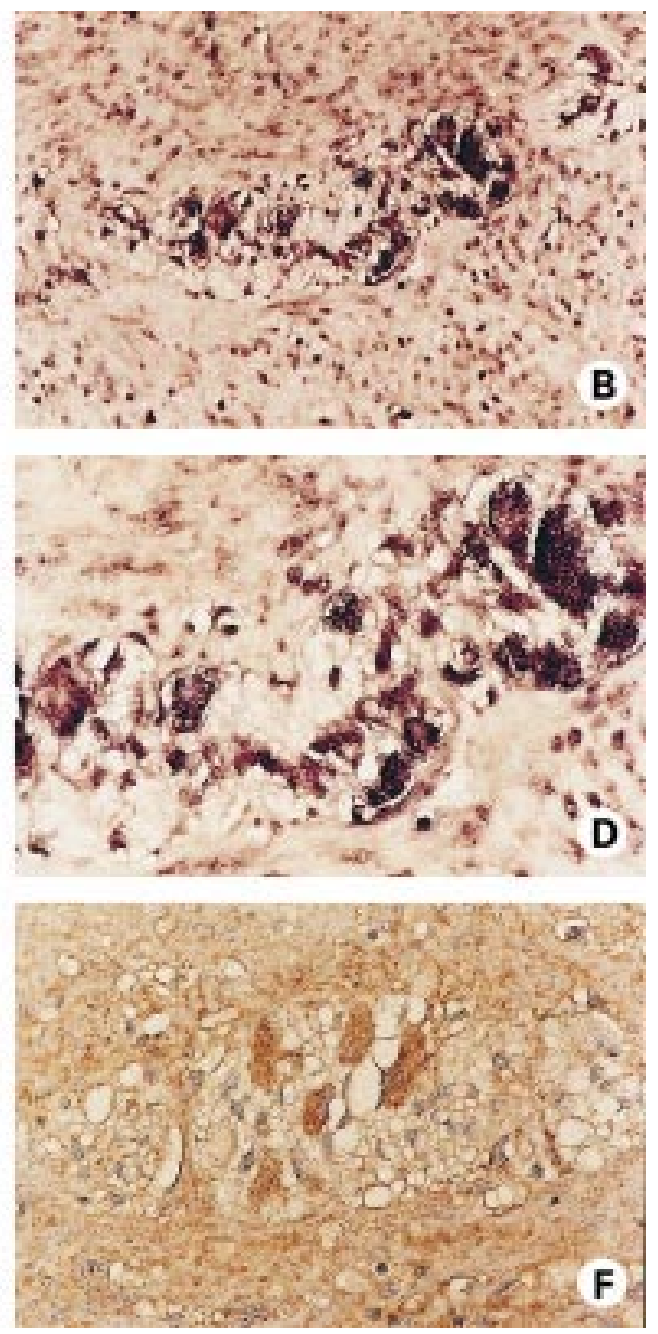

Figure 4 Localisation of neurokinin-1 receptor (NK-1R) expression in non-inflamed $(A, C$, and $E)$, and inflamed Crohn's disease $(C D)(B, D, F)$ myenteric plexus by in situ hybridisation $(A-D)$, and immunohistochemistry $(E, F)$. $(A)$ NK-1R mRNA (purple) is detected in enteric neurones of the myenteric plexus of normal colon. (C) Higher magnification view of $(A)$. (E) NK-1R protein (brown) staining is evident in the myenteric plexus of normal colon. Section was counterstained with haematoxylin (blue). (B) Expression of NK-1R $m R N A$ by enteric neurones of the myenteric plexus of $C D$ colon. Note the NK-1R positive cells of lymphoid morphology. (D) Higher magnification view of (B). (F)

Immunohistochemical detection of $N K-1 R$ protein expression (brown) in the myenteric plexus of $C D$ colon. Section was counterstained with haematoxylin (blue). 
A
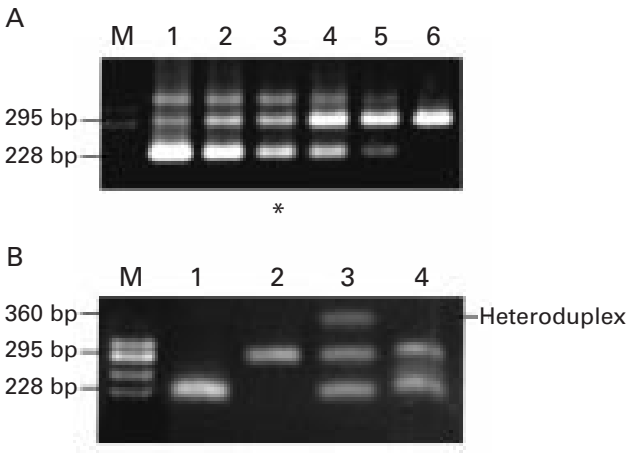

Figure 5 Quantitation of neurokinin-1 receptor (NK-1R) $m R N A$ expression in a mucosal biopsy from active ulcerative colitis (UC) colon. (A) Gel shows a representative NK-1R $m R N A$ quantitation using qcRT-PCR. Competitive standards were spiked into the aliquoted biopsy RNA sample at concentrations ranging from $2.6 \times 10^{4}$ molecules to $2.6 \times 10^{2}$ molecules lanes $1-6$; 2.5-fold dilution series). Equivalence $\left(^{\star}\right)$ is seen at $4.1 \times 10^{3}$ NK-1R $m$ RNA molecules, in which target (295 bp) and competitive standard (228 bp) PCR products are of equal band intensity (lane 3). When adjusted for the amount of total RNA in the assay, this represents a level of expression of $4.1 \times 10^{4} N K-1 R m R N A$ transcripts/ $\mu \mathrm{g} R A$ in this particular UC biopsy sample. HaeIII digested $\phi X 174 \mathrm{DNA}$ size markers (M) were used. (B) Confirmation of heteroduplex formation. A third band of slower electrophoretic mobility ( $-360 \mathrm{bp})$ than the target (295 bp) or competitor (228 bp) PCR products was observed when the concentration of both was relatively high (lane 3). This was absent when competitor or target were amplified separately (lanes 1 and 2 , respectively). To confirm that the $360 \mathrm{bp}$ band consisted of a heteroduplex between one strand each of target and competitor PCR products, the PCR products from lane 3 were subjected to digestion with the single stranded DNA specific nuclease, S1 (lane 4). This treatment eliminated the $360 \mathrm{bp}$ band, confirming the presence of a single stranded "loop out" amenable to S1 digestion, which is characteristic of the predicted heteroduplex.

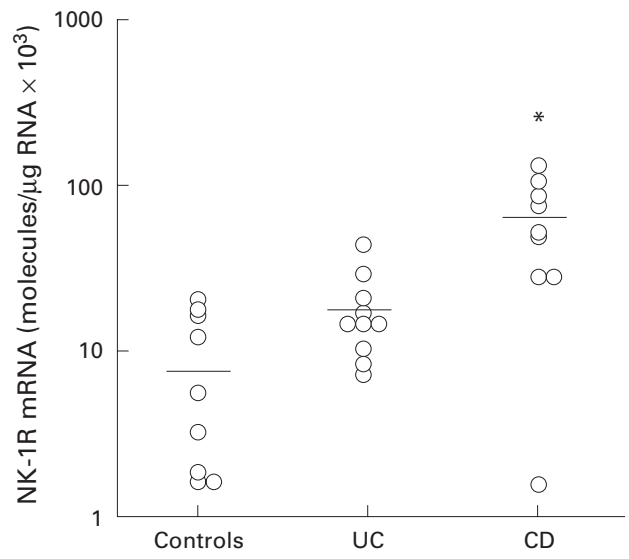

Figure 6 Neurokinin-1 receptor (NK-1R) $m R N A$ levels in mucosal biopsies from normal colon $(n=9)$, active ulcerative colitis (UC) colon $(n=10)$, and active Crohn's disease $(C D)$ colon $(n=10)$. The bar indicates mean $N K-1 R m R N A$ expression in each group. ${ }^{\star} p<0.01$.

NK-1R mRNA levels displayed significant upregulation compared with normal mucosal expression levels $(\mathrm{p}<0.01)$. The biopsy levels of NK-1R mRNA were consistent within each group (control, UC, and CD) (fig 6), and in the IBD biopsies NK-1R mRNA level was independent of corticosteroid treatment (UC $n=4$ / 10; $\mathrm{CD} n=4 / 10)$. This agrees with previous findings that the level of colonic SP binding sites in IBD is not modified by corticosteroid or other anti-inflammatory therapies. ${ }^{34}$

\section{Discussion}

In this study, we used the definitive resolution of in situ hybridisation and immunohistochemistry to examine the cellular targets for SP binding via the neurokinin-1 receptor in normal compared with inflamed IBD colon. We also used the exquisite sensitivity of competitive RT-PCR to quantitate NK-1R expression at the mRNA level in biopsies of normal and IBD colonic mucosa. Our results demonstrated that although the phenotype of NK-1R expressing cells was not altered in IBD, increased numbers of NK-1R positive lymphoid cells were observed in IBD tissue. In addition, the pattern of epithelial NK-1R expression was found to be altered in UC while increased NK-1R expression was observed in the myenteric plexus of CD. Furthermore, we found that inflamed IBD mucosa exhibited significantly increased expression of NK-1R mRNA compared with normal mucosal levels.

Using the complementary techniques of in situ hybridisation and immunohistochemistry, $\mathrm{NK}-1 \mathrm{R}$ mRNA and protein expression were detected in LPMC, lymphoid follicles, surface and crypt epithelium, submucosal arterioles and venules, circular and longitudinal smooth muscle, and myenteric plexus of normal colonic resections. This cellular distribution of NK-1R expression complements recent work by Smith et al which demonstrated NK-1R immunoreactivity in circular muscle, myenteric and submucosal neurones, mucosal cells, and endothelial cells of human antrum and duodenum. ${ }^{47}$ We further localised the vascular expression of NK-1R to endothelium and smooth muscle of arterioles and venules. This finding agrees with reports of SP binding sites in human vascular endothelium. ${ }^{47} 48$

We did not observe any ectopic expression of NK-1R in IBD. However, we found increased numbers of $\mathrm{NK}-1 \mathrm{R}$ bearing lymphoid cells in IBD tissue, aberrant negative epithelial expression of NK-1R in UC, and increased NK-1R expression in $\mathrm{CD}$ myenteric plexus. We also found upregulated levels of NK-1R mRNA in IBD mucosal biopsies. Our observed increase in IBD NK-1R mRNA levels could be attributed to increased infiltration of NK-1R mRNA positive lymphoid cells in inflamed mucosa. Alternatively, cellular expression of NK-1R mRNA may be upregulated in LPMC from actively inflamed mucosa. Activation of macrophages with LPS has been shown to upregulate NK-1R mRNA expression. ${ }^{49}$ We have previously demonstrated upregulation of NK-1R mRNA expression on activation of the human IM-9 B lymphoblastoid cell line with PMA and ionomycin. ${ }^{50}$ Quantitation of NK-1R mRNA levels in LPMC isolated from normal or actively inflamed colonic mucosa did not reveal any differences in cellular expression levels. ${ }^{50}$ While this favours the view that NK-1R expression is not upregulated in individual LPMC during inflammation, it must also be considered that isolated LPMC may not be reflective of LPMC in situ in the mucosal microenvironment.

Aberrant negative epithelial expression of $\mathrm{NK}-1 \mathrm{R}$ was observed in UC colonic resections 
and was rarely detected in CD. Negative epithelial expression of $\mathrm{NK}-1 \mathrm{R}$ in UC may perhaps account for the lower NK-1R mRNA levels detected in UC mucosal biopsies compared with CD mucosal biopsies $(p<0.01)$. Intestinal epithelial expression of $\mathrm{NK}-1 \mathrm{R}$ mRNA has been reported to be upregulated in Clostridium difficile toxin A enteritis. ${ }^{51} \mathrm{C}$ difficile infection of the gut has also been shown to stimulate local expression of proinflammatory cytokines. ${ }^{52}$ We have recently demonstrated induction of $\mathrm{NK}-1 \mathrm{R}$ expression in human colonic epithelial cell lines by the proinflammatory Th 1 cytokines interferon $\gamma, \mathrm{TNF}-\alpha$, and IL-1 $\beta$ (manuscript submitted). A Th1 cytokine profile was associated with $\mathrm{CD} .{ }^{53}{ }^{54}$ Cytokine patterns in UC have not demonstrated a distinct Th 1 or Th2 phenotype. ${ }^{54}{ }^{55}$ Differences in cytokine profiles may possibly explain the observed differences in epithelial NK-1R expression between CD and UC.

There are marked structural abnormalities of the enteric nervous system in IBD. ${ }^{56}$ Changes are more pronounced in $\mathrm{CD}$ and involve hyperplasia of ganglion cells, extensive axonal degeneration, and infiltration of the plexus with plasma cells, mast cells, and lymphocytes. ${ }^{447}$ Examination of NK-1R expression by enteric neurones revealed intense staining of CD myenteric plexus compared with normal myenteric plexus. Upregulation of SP binding sites on enteric neurones has been described in CD. ${ }^{34}$ Increased NK-1R detection in CD myenteric plexus could be attributed to hyperplasia of NK-1R positive ganglion cells, infiltration of NK-1R positive lymphoid cells, or increased nociception. Nociception induced upregulation of NK-1R mRNA has been reported in dorsal root ganglion neurones of rats with hind paw inflammation..$^{58} 59$

In conclusion, we have localised cellular expression of NK-1R to LPMC, lymphoid follicles, epithelia, submucosal vasculature, smooth muscle, and myenteric plexus of IBD colon. In all specimens, localisation of NK-1R mRNA by in situ hybridisation and NK-1R protein by immunohistochemistry were in perfect concordance, confirming cellular sites of NK-1R expression. We have also demonstrated increased numbers of NK-1R bearing cells in IBD tissue, aberrant negative epithelial expression of NK-1R in UC, increased expression of $\mathrm{NK}-1 \mathrm{R}$ in $\mathrm{CD}$ myenteric plexus, and upregulated levels of NK-1R mRNA in IBD mucosal biopsies. The greater upregulation of NK-1R mRNA in CD versus UC biopsies, as determined by quantitative RT-PCR, may reflect the more uniform epithelial expression and myenteric plexus upregulation of NK-1R observed in situ in CD. This is also supported by our observation of no marked differences in the level of NK-1R positive inflammatory cells between $\mathrm{CD}$ and UC. The increased expression of NK-1R in CD versus UC suggests that substance $\mathrm{P}$ may be relatively more important in the pathophysiology of CD than previously suggested by reports that SP itself is elevated more in UC. ${ }^{25-28}$ The increased expression of $\mathrm{NK}-1 \mathrm{R}$ in the CD myenteric plexus might indicate that primary neural mechanisms may be relatively more important in the pathophysiology of CD than UC. Our results suggest that there are differences between CD and UC in how the effects of SP are regulated. Increased neuronal expression and more uniform epithelial expression of $\mathrm{NK}-1 \mathrm{R}$ in $\mathrm{CD}$ may imply greater responsiveness to limited amounts of SP. On the other hand, lack of upregulation of $\mathrm{NK}-1 \mathrm{R}$ in UC myenteric plexus might favour lower responsiveness to the higher levels of SP present in UC. Epithelial cells in UC may also downregulate their responsiveness to SP by loss of NK-1R expression. Our findings demonstrate the likely cellular targets for pharmacological NK-1R antagonists, and thereby suggest the potential beneficial effects of such agents on the many pathophysiological symptoms of IBD.

Grant support was obtained from the following: Health Research Board of Ireland; Wellcome Trust; Bing Foundation; Peptide Biochemistry Core of CURE: Digestive Diseases Research Centre (DK 41301); VA Greater Los Angeles Health Care System (90073).

1 Payan DG. Neuropeptides and inflammation: the role of substance P. Ann Rev Med 1989;40:341-52.

2 McGillis JP, Mitsuhashi M, Payan DG. Immunologic properties of substance P. In: Ader R, ed. Psychoneuroimmunol ogy, 2nd edn. London: Academic Press, 1991:209-23.

3 Moore TC, Lami JL, Spruck CH. Substance P increases lymphocyte traffic and lymph flow through peripheral lymph nodes of sheep. Immunology 1989;67:109-14.

4 Stanisz AM, Befus D, Bienenstock J. Differential effects of vasoactive intestinal peptide, substance $P$, and somatostatin on immunoglobulin synthesis and proliferation by lymphocytes from Peyer's patches, mesenteric lymph nodes, and spleen. F Immunol 1986;136:152-6.

5 Payan DG, Brewster DR, Goetzl EJ. Specific stimulation of human $\mathrm{T}$ lymphocytes by substance P. f Immunol human T lymphocy

6 Bost KL, Pascual DW. Substance P: a late acting B lymphocyte differentiation cofactor. Am f Physiol 1992; 262: $5537-45$

7 Haines KA, Kolasinski SL, Cronstein BN, et al. Chemoattraction of neutrophils by substance $\mathrm{P}$ and transforming rowth factor- $\beta 1$ is inadequately explained by current models of lipid remodelling. F Immunol 1993;151:1491-9.

8 Bar-Shavit Z, Goldman R, Stabinsky Y, et al. Enhancement of phagocytosis - a newly found activity of substance P residing in it's N-terminal tetrapeptide sequence. Biochem Biophys Res Commun 1980;94:1445-51.

9 Shanahan F, Denburg JA, Fox J, et al. Mast cell heterogeneity: effects of neuroenteric peptides on histamine release. F Immunol 1985;135:1331-7.

10 Lotz M, Vaughan JH, Carson DA. Effect of neuropeptides on production of inflammatory cytokines by human monoon production of inflammatory cy
cytes. Science $1988 ; 241: 1218-21$.

11 Ho W-Z, Kaufman D, Uvaydova M, et al. Substance P augments interleukin-10 and tumour necrosis factor-alpha release by human cord monocytes and macrophages. $\mathcal{F}$ Neuroimmunol 1996;71:73-80.

12 Pernow B. Substance P. Pharmacol Rev 1983;53:85-141

3 Maggi CA. Capsaicin-sensitive nerves in the gastrointestinal tract. Arch Int Pharmacol 1990;303:157-66.

14 Sundler F, Hakanson R, Larsson L-I, et al. Substance P in the gut: immunohistochemical and immunocytochemical study of distribution and development. In: von Euler US, Pernow B, eds. Substance P. New York: Raven Press, 1977: $59-65$.

15 Shanahan F, Anton PA. Role of peptides in the regulation of the mucosal immune and inflammatory response. In: Walsh JH, Dockray GJ, eds. Gut peptides: biochemistry and physiology. New York: Raven Press, 1994:851-67.

16 Reinshagen M, Egger B, Procaccino F, et al. Neuropeptides in inflammatory bowel disease: an update. Inflamm Bowel in inflammatory bow

17 Swain MG, Agro A, Blennerhasset P, et al. Increased levels of substance $P$ in the myenteric plexus of Trichinellainfected rats. Gastroenterology 1992;102:1913-19.

18 Agro A, Stanisz AM. Inhibition of murine intestinal inflammation by anti-substance P antibody. Reg Immunol 1993;5: $120-6$.

19 Kataeva G, Agro A, Stanisz AM. Substance P-mediated intestinal inflammation: inhibitory effects of $\mathrm{CP} 96,345$ and SMS 201-995. Neuroimmunomodulation 1994;1:3506.

20 Pothoulakis C, Castagliuolo I, LaMont TJ, et al. CP-96,345, a substance $P$ antagonist, inhibits rat intestinal responses to Clostridium difficile toxin A but not cholera toxin. Proc Natl Acad Sci USA 1994;91:947-51.

21 Mantyh CR, Pappas TN, Lapp JA, et al. Substance P activation of enteric neurones in response to intraluminal 
Clostridium difficile toxin A in the rat ileum. Gastroenterology 1996;111:1272-80

22 Castagliuolo I, LaMont JT, Letourneau R, et al. Neuronal involvement in the intestinal effects of Clostridium difficile toxin A and Vibrio cholerae enterotoxin in rat ileum. Gastroenterology 1994;107:657-65.

23 Castagiuolo I, Riegler M, Pasha A, et al. Neurokinin$1(\mathrm{NK}-1)$ receptor is required in Clostridium difficileinduced enteritis. F Clin Invest 1998;101:1547-50.

24 Wood JD, Peck OC, Sharma HS, et al. A non-peptide neurokinin-1 (NK-1) receptor antagonist suppresses initiation of acute inflammation in the colon of the cotton-top tamarin model for spontaneous colitis and colon cancer. Gastroenterology 1996;110:A1047.

25 Bernstein CN, Robert ME, Eysselein VE. Rectal substance $\mathrm{P}$ concentrations are increased in ulcerative colitis but not in Crohn's disease. Am $\mathcal{7}$ Gastroenterol 1993;88:908-13.

26 Yamamoto H, Morise K, Kusugami K, et al. Abnormal neuropeptide concentration in rectal mucosa of patients with inflammatory bowel disease. $\mathcal{F}$ Gastroenterol 1996;31:52532 .

27 Koch TR, Carney A, Go VLW. Distribution and quantitation of gut neuropeptides in normal intestine and

28 Goldin E, Karmeli F, Selinger Z, et al. Colonic substance P levels are increased in ulcerative colitis and decreased in chronic severe constipation. Dig Dis Sci 1989;34:754-7.

29 Mazumdar S, Moy Das K. Immunocytochemical localisation of vasoactive intestinal peptide and substance $P$ in the colon from normal subjects and patients with inflammatory bowel disease. Am $\mathcal{F}$ Gastroenterol 1992;87:176-81.

30 Keranen U, Kiviluoto T, Jarvinen $\mathrm{H}$, et al. Changes in substance P-immunoreactive innervation of human colon associated with ulcerative colitis. Dig Dis Sci 1995;40: 2250-8.

31 Watanabe T, Kubota Y, Muto T. Substance P containing nerve fibres in rectal mucosa of ulcerative colitis. Dis Colon Rectum 1997;40:718-25.

32 Kimura M, Masuda T, Hiwatashi N, et al. Changes in neuropeptide-containing nerves in human colonic mucosa neuropeptide-containing nerves in human colonic mucosa with

33 Mantyh CR, Gates TS, Zimmermann RP, et al. Receptor binding sites for substance $\mathrm{P}$, but not substance $\mathrm{K}$ or neuromedin $\mathrm{K}$, are expressed in high concentrations by arterioles, venules, and lymph nodules in surgical specimens obtained from patients with ulcerative colitis and Crohn's disease. Proc Natl Acad Sci USA 1988;85:3235-9.

34 Mantyh CR, Vigna SR, Bollinger RR, et al. Differential expression of substance $\mathrm{P}$ receptors in patients with Crohn's disease and ulcerative colitis. Gastroenterology 1995;109:850-60.

35 Mantyh PW, Allen CJ, Ghilardi JR, et al. Rapid endocytosis of a G protein-coupled receptor: Substance P- evoked internalisation of it's receptor in the rat stratum in vivo. Proc Natl Acad Sci USA 1995;92:2622-6.

36 Garland AM, Grady EF, Payan DG, et al. Agonist-induced internalisation of the substance $\mathrm{P}\left(\mathrm{NK}_{1}\right)$ receptor expressed internalisation of the substance $\mathrm{P}\left(\mathrm{NK}_{1}\right)$ recept
in epithelial cells. Biochem $\mathcal{f} 1994 ; 303: 177-86$.

37 Joslin G, Krause JE, Hershey AD, et al. Amyloid $\beta$-protein, substance P and bombesin bind to the serpin-enzyme comsubstance $P$ and bombesin bind to the serpin-enz

38 Marasco WA, Showell HJ, Becker EL. Substance P binds to the formylpeptide chemotaxis receptor on the rabbit neutrophil. Biochem Biophys Res Commun 1981;99:106572 .

39 Jensen RT, Coy DH. Progress in the development of poten bombesin receptor antagonists. Trends Pharmacol Sci 1991; 12:13-19.
40 Targan S, Shanahan F, eds. Inflammatory bowel disease: from bench to bedside. Baltimore: Williams and Wilkins, 1994.

41 Chomczynski P, Saachi N. Single-step method of RNA isolation by guanidium thiocyanate-phenol-chloroform extraction. Anal Biochem 1987;162:156-9.

42 O'Connell J, Goode T, Shanahan F. Quantitative measurement of mRNA expression by competitive RT-PCR. Methods Mol Biol 1998;92:183-93.

43 Goode T, O'Connell J, Sternini C, et al. Substance P (neurokinin-1) receptor is a marker of human mucosal but not peripheral mononuclear cells: molecular quantitation and localisation. F Immunol 1998;161:2232-40.

44 Davis DR, Dockerty MB, Mayo CW. The myenteric plexus in regional enteritis: a study of the number of ganglion cells in the ileum in 24 cases. Surg Gynecol Obstet 1955;101:20816.

45 Dockray GJ. Substance P and other tachykinins. In: Walsh $\mathrm{JH}$, Dockray GJ, eds. Gut peptides: biochemistry and physiology. New York: Raven Press, 1994:401-22.

46 Piatak M, Luk K, Williams B, et al. Quantitative competitive polymerase chain reaction for accurate quantitation of HIV DNA and RNA species. Biotechniques 1993;14:70-81.

47 Smith VC, Sagot MA, Couraud J-Y, et al. Localisation of the neurokinin 1 (NK-1) receptor in the human antrum and duodenum. Neurosci Lett 1998;253:49-52.

48 Greeno EW, Mantyh P, Vercellotti GM, et al. Functional neurokinin 1 receptors for substance $\mathrm{P}$ are expressed by human vascular endothelium. 7 Exp Med 1993:177:126976.

49 Bost KL, Breeding SAL, Pascual DW. Modulation of the mRNAs encoding substance $P$ and it's receptor in rat macrophage by LPS. Reg Immunol 1992;4:105-12.

50 Goode C, O'Connell J, O'Sullivan GC, et al. Cellular localisation and quantitation of substance $\mathrm{P}(\mathrm{NK}-1)$ receptor mRNA in normal and inflamed human colonic mucosa. Gastroenterology 1997;112:A982.

51 Pothoulakis C, Castagliuolo I, Leeman SE, et al. Substance P receptor expression in intestinal epithelium in Clostridium difficile toxin A enteritis in rats. Am 7 Physiol 1998;275: G68-75.

52 Castagliuolo I, Keates AC, Wang CC, et al. Clostridium difficile toxin A stimulates macrophage-inflammatory protein-2 production in rat intestinal epithelial cells. F Immunol 1998; 160:6039-45.

53 Desreumaux P, Brandt E, Gambiez L, et al. Distinct cytokine patterns in early and chronic ileal lesions of Crohn's disease. Gastroenterology 1997;113:118-26.

54 Fuss IJ, Neurath $M$, Boirivant $M$, et al. Disparate CD $4^{+}$ lamina propria (LP) lymphokine secretion profiles in

55 Neissner M, Volk BA. Altered Th1/Th2 cytokine profiles in the intestinal mucosa of patients with inflammatory bowel disease as assessed by quantitative reversed transcribed polymerase chain reaction (RT-PCR). Clin Exp Immunol 1995;101:428-35

56 Shanahan F. Enteric neuropathophysiology and inflammatory bowel disease. Neurogastroenterology 1998;10:185-7.

57 Dvorak AM, Connell AB, Dickersin GR. Crohn's disease: a scanning electron microscopic study. Hum Pathol 1979;10: $165-77$.

58 Krause JE, DiMaggio DA, McCarson KE. Alterations in neurokinin-1 receptor gene expression in models of pain and inflammation. Can $\mathcal{F}$ Physiol Pharmacol 1995;73:854-9.

59 Schafer MK-H, Nohr D, Krause JE, et al. Inflammationinduced upregulation of NK1 receptor mRNA in dorsal horn neurones. Neuroreport 1993;4:1007-10. 